\title{
Dosimetric comparison of organs at risk using different contouring guidelines for definition of the clinical target volume in anal cancer
}

\author{
Hendrik Dapper ${ }^{1}$ Markus Oechsner ${ }^{1} \cdot$ Stefan Münch ${ }^{1,2}$. Christian Diehl ${ }^{1} \cdot$ Jan C. Peeken ${ }^{1,2,3} \cdot$ Kai Borm $^{1}$. \\ Stephanie E. Combs ${ }^{1,2,3}$
}

Received: 1 December 2019 / Accepted: 16 January 2020 / Published online: 3 February 2020

(c) The Author(s) 2020

\begin{abstract}
Background There are different contouring guidelines for definition of the clinical target volume (CTV) for intensitymodulated radiation therapy (IMRT) of anal cancer (AC). We conducted a planning comparison study to evaluate and compare the dose to relevant organs at risk (OARs) while using different CTV definitions.

Methods Twelve patients with a primary diagnosis of anal cancer, who were treated with primary chemoradiation (CRT), were selected. We generated four guideline-specific CTVs and subsequently planned target volumes (PTVs) on the planning CT scan of each patient. An IMRT plan for volumetric arc therapy (VMAT) was set up for each PTV. Dose parameters of the planned target volume (PTV) and OARs were evaluated and compared, too.

Results The mean volume of the four PTVs ranged from $2138 \mathrm{cc}$ to $2433 \mathrm{cc}$. The target volumes contoured by the authors based on the recommendations of each group were similar in the pelvis, while they differed significantly in the inguinal region. There were no significant differences between the four target volumes with regard to the dose parameters of the cranially located OARs. Conversely, some dose parameters concerning the genitals and the skin varied significantly among the different guidelines.

Conclusion The four contouring guidelines differ significantly concerning the inguinal region. In order to avoid inguinal recurrence and to protect relevant OARs, further investigations are needed to generate uniform standards for definition of the elective clinical target volume in the inguinal region.
\end{abstract}

Keywords Anal cancer · Contouring guidelines · Organs at risk · Dose distribution · Inguinal lymph nodes

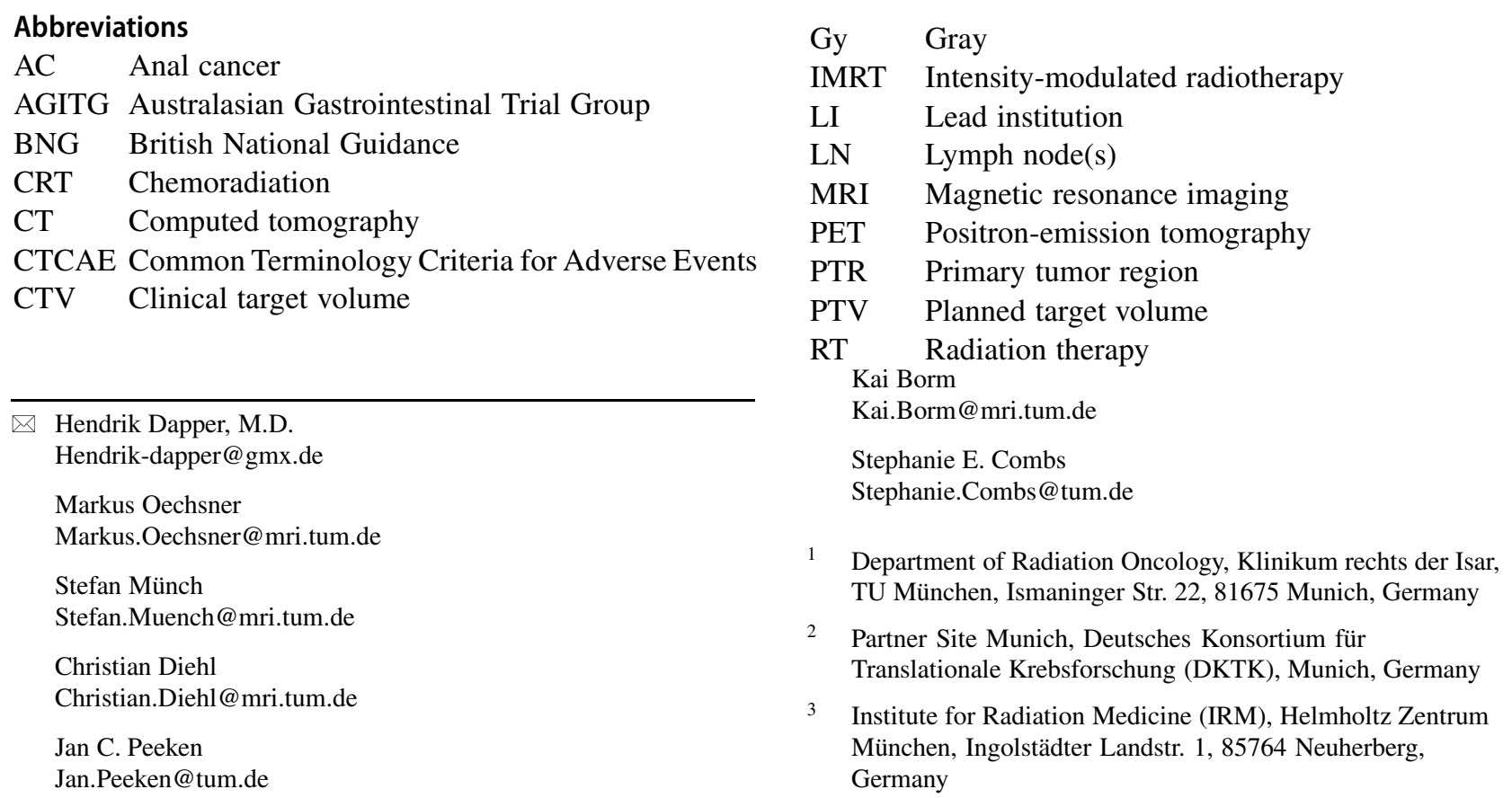


RTOG Radiation Therapy Oncology Group

VMAT Volumetric arc therapy

\section{Background}

Anal cancer (AC) is a relatively rare malignant tumor of the lower gastrointestinal tract. Chemoradiation (CRT) has been established as an organ-preserving standard approach in non-metastatic disease and is associated with good overall survival rates [1, 2]. So far, the most relevant prognostic factors correlating with survival endpoints are locoregional lymph node (LN) involvement, primary tumor size $>5 \mathrm{~cm}$, and pathological complete response [3]. Currently, three international recommendations for intensity-modulated radiation therapy (IMRT) exist for definition of the clinical target volume (CTV) of AC. These were published by the Radiation Therapy Oncology Group (RTOG), the Australasian Gastro-Intestinal Trial Group (AGITG), and the authors and collaborative groups of the British National Guidance (BNG) [4-6]. The AGITG rightly pointed out that there is currently not sufficient evidence regarding the definition of the inguinal lymphatic drainage [6]. The inguinal region is affected primarily or metachronously in up to $40 \%$ of all AC patients [7-9]. In a recent PET imagingbased analysis of patterns of LN involvement in primary $\mathrm{AC}$, we (the lead institution) were able to demonstrate that the three guidelines differ in their hypothetical effectiveness to cover microscopic LN metastases. Based on these results, we worked out a recommendation for CTV delineation of the inguinal region [10]. Achieving the best possible locoregional control is an important objective in the treatment of AC. However, typical complications such as dermatological, genitourinary, and gastrointestinal side effects, and others like vaginal stenosis, hip osteoarthritis, or sexual dysfunction play a decisive role and should always be considered during treatment planning [11-15].

In order to be able to estimate the efficiency regarding locoregional control rates and potential side effects of the different guidelines, we conducted a comparative study on the various CTVs and determined the dose to OARs.

\section{Methods}

We selected 12 patients with the primary diagnosis of squamous cell AC who were treated with CRT at our institution between 2012 and 2018. In all patients, we retrospectively generated the three different CTVs of the established guidelines and a fourth CTV using our own guidelines (LI) on the original planning CT scan with a slice thickness of $3 \mathrm{~mm}$ (all prone position). All guidelines are very similar regarding their recommendations for delineation of the elective
LN regions in the pelvis (internal/external iliac, pre-sacral, internal obturatoric). There are, however, significant differences regarding the mesorectal and ischiorectal fossa and especially the inguinal region. For the essential contents of the guidelines, see Table 1. With regard to uncertainties leaving room for interpretation of the different definitions of the target volume, formulations such as "should be contoured as a compartment," we tried to refer as much as possible to the respective atlases published. The planning target volume of the inguinal region (PTVing) was created by a 6-mm outer margin of the respective CTV. The planning target volume of the pelvic region which included the primary tumor region (PTV pelvic) was conceived by increasing the CTV by $10 \mathrm{~mm}$ in all directions. The PTV was always limited to the surface of the body. Afterwards, mostly based on the pelvic normal tissue atlas of RTOG, the vulva, scrotum, femoral heads, small bowel, rectum, sigmoid colon, and the urinary bladder were defined [16]. The skin was determined as the volume that represents the first $3 \mathrm{~mm}$ of the body surface into the body. We also outlined the genitalia analogously to the genitalia contouring guidelines of Brooks et al. [17].

Subsequently, we created a main and a boost plan for the four different distinct PTVs in each individual for volumetric modulated arc therapy (VMAT) intended to be irradiated on a Varian Clinac ${ }^{\circledR}$ DHX linear accelerator (Varian Medical Systems, Palo Alto, CA, USA). The primary tumor region (PTR) and the pelvic LNs were supposed to receive a total dose of $50.4 \mathrm{~Gy}$ and the inguinal LNs were supposed to receive a total dose of $36 \mathrm{~Gy}$ ( single dose $1.8 \mathrm{~Gy}$ ). For the main plan, the dose prescription was $36 \mathrm{~Gy}$ (1.8 Gy single dose) to PTV1 (PTV ${ }^{\text {pelvic }}+$ PTV $^{\text {ing }}$ ), which included the PTR and the elective pelvic and inguinal LNs. 14.4Gy (1.8 Gy single dose) was prescribed to PTV2 (PTV ${ }^{\text {pelvic}}$ ) including the PTR and the elective pelvic LNs, disregarding the inguinal LNs for the sequential boost. The dose constraints for OARs based on Quantitative Analyses of Normal Tissue Effects in the Clinic (QUANTEC) [21]. For VMAT, we regularly used three arcs in the main plan (PTV1) and two arcs for the boost plan (PTV2; 6 or $15 \mathrm{MV}$ ). The dose was prescribed to the median of the PTV (ICRU83) [18]. The software used for structure definition and dose comparison was Eclipse Treatment Planning System 13.0 (Varian Medical Systems, Palo Alto, CA, USA).

A Friedman test using SPSS 25.0 (SPSS Inc, Chicago, IL, USA) was applied to identify significant differences between the four plans with regard to all dose parameters of the PTV and the OAR. A post hoc analysis was performed to find out whether any significant differences between the individual plans of RTOG, AGITG, BNG, and LI could be identified. A $p$-value $<0.05$ was considered to indicate statistical significance. 
Table 1 Overview of the three major guidelines and the TUM guideline for elective CTV definition for IMRT of primary anal cancer

\begin{tabular}{|c|c|c|c|c|}
\hline Elective CTV & RTOG & AGITG & $\mathrm{BNG}$ & TUM \\
\hline Cranial & \multicolumn{4}{|c|}{$\begin{array}{l}\text { All: bifurcation of the common iliac artery/level of the recto-sigmoid junction } \\
\text { RTOG: or } 2 \mathrm{~cm} \text { above the most cranial aspect of a macroscopic tumor } \\
\text { BNG: if NO mesorectal: the lower } 50 \mathrm{~mm} \text { of the mesorectum }\end{array}$} \\
\hline Pelvis & \multicolumn{4}{|c|}{$\begin{array}{l}\text { All: inclusion of internal and external iliac, presacral nodes, para-rectal, mesorectal nodes } \\
\text { AGITG: inclusion of the ischiorectal fossa }\end{array}$} \\
\hline \multirow{4}{*}{$\begin{array}{l}\text { Caudal } \\
\text { (inguinal } \\
\text { LN) }\end{array}$} & Radial: & Radial: & Radial: & Radial: \\
\hline & $\begin{array}{l}\text { "As a compartment with any } \\
\text { identified nodes" }\end{array}$ & $\begin{array}{l}\text { "As a compartment", an- } \\
\text { terior } 20 \mathrm{~mm} \text { and medial } \\
10-20 \mathrm{~mm} \text { of femoral ves- } \\
\text { sels }\end{array}$ & $\begin{array}{l}\text { "As a compartment", an- } \\
\text { terior } 5 \mathrm{~mm} \text { from skin and } \\
\text { medial the spermatic cord }\end{array}$ & $\begin{array}{l}2 \mathrm{~cm} \text { of femoral vessels. } \\
1 \mathrm{~cm} \text { of great saphenous } \\
\text { vein. } 3 \mathrm{~cm} \text { at superomedial } \\
\text { and superolateral superficial } \\
\text { nodes }\end{array}$ \\
\hline & Caudal: & Caudal: & Caudal: & Caudal: \\
\hline & $\begin{array}{l}2 \mathrm{~cm} \text { caudal to the saphe- } \\
\text { nous/femoral junction }\end{array}$ & $\begin{array}{l}\text { Lower edge of the ischial } \\
\text { tuberosities }\end{array}$ & Lesser trochanter & $\begin{array}{l}\text { Anal verge, high risk: in- } \\
\text { clusion of ano-inguinal } \\
\text { lymphatic drainage }\end{array}$ \\
\hline
\end{tabular}

CTV clinical target volume; LN lymph nodes; RTOG Radiation Therapy Oncology Group; AGITG Australasian Gastro-Intestinal Trial Group; $B N G$ British National Guidance; TUM Technical University Munich (suggestions from retrospective analysis of inguinal patterns of LN involvement); $A I L D$ ano-inguinal lymphatic drainage

\section{Results}

\section{Patients' characteristics}

In accordance with the gender-specific incidence, we chose eight female and four male patients. The median age at diagnosis was 57 years (range: 41-78). Two patients were staged T1, five T2, four T3, and one patient T4. Seven patients initially showed positive LNs. This ultimately resulted in two patients with UICC stage I, three patients with stage II, and seven with stage III disease. Median BMI was $28 \mathrm{~kg} / \mathrm{m}^{2}$ (range: $17-41$ ).

\section{PTV volumes and plan value}

The mean volumes of the PTVs of the RTOG, AGITG, BNG, and LI groups amounted to 2138 cc, 2407 cc, 2419 cc, and $2433 \mathrm{cc}$, respectively. In accordance with the distinct contouring guidelines, all CTVs had the same cranial border (the bifurcation of the common iliac artery plus $1 \mathrm{~cm}$ ). The caudal and radial margins at the inguinale site, however, differed (Table 1, Fig. 1). All volumes were significantly larger $(\approx 10 \%)$ compared to the volume of the RTOG, whereas no significant differences between the three PTV volumes of the AGITG, BNG, and LI groups could be identified. Taking only the PTV volumes of the inguinal region into consideration, the results of the four groups differed greatly. All inguinal PTV volumes were significantly higher compared to RTOG $(<0.001)$. With $660 \mathrm{cc}$, the inguinal PTV of the BNG was almost twice as high as the PTV of the RTOG ( $363 \mathrm{cc}$ ). The PTV of the LI, however, was similar to that of the BNG $(651 \mathrm{cc})$. The PTV of the AGITG was $500 \mathrm{cc}$ and thus significantly smaller than the PTV of the BNG $(p=0.016)$.
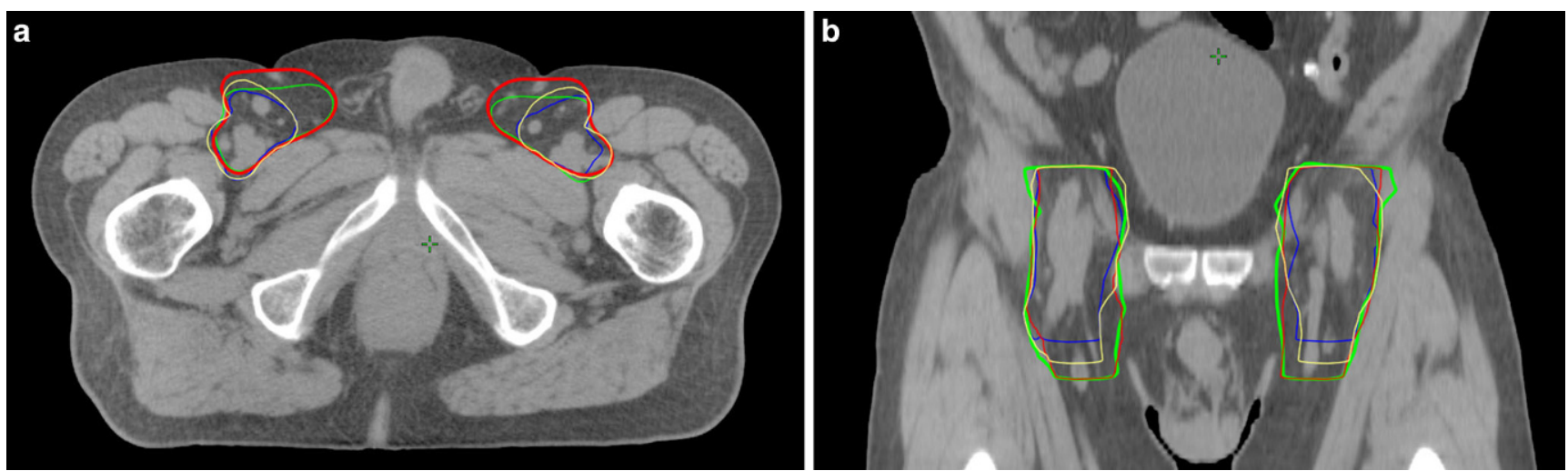

Fig. 1 Differences in inguinal clinical target volumes using four different contouring guidelines for intensity-modulated radiotherapy of elective target volumes in primary treatment of anal cancer (AC) (a axial, b coronal). Blue Radiation Therapy Oncology Group, yellow Australasian Gastrointestinal Trials Group, green Leading Institute, red British National Guidance 
Table 2 Absolute dose parameters of organs at risk for different cranial PTVs

\begin{tabular}{|c|c|c|c|c|c|}
\hline Structure & Parameter & $\begin{array}{l}\text { RTOG } \\
\text { Gy }\end{array}$ & AGITG & BNG & TUM \\
\hline \multirow[t]{3}{*}{ Rectum } & Dmean & 50.4 & 50.2 & 50.2 & 50.3 \\
\hline & D98\% & 48.9 & 48.9 & 49.0 & 49.0 \\
\hline & $\mathrm{D} 2 \%$ & 52.0 & 52.1 & 52.0 & 52.0 \\
\hline \multirow{3}{*}{$\begin{array}{l}\text { Sigmoid } \\
\text { colon }\end{array}$} & Dmean & 45.7 & 45.7 & 45.8 & 45.7 \\
\hline & D98\% & 27.8 & 28.0 & 27.9 & 27.6 \\
\hline & $\mathrm{D} 2 \%$ & 50.3 & 50.3 & 50.4 & 50.3 \\
\hline \multirow{3}{*}{$\begin{array}{l}\text { Femoral } \\
\text { head }\end{array}$} & Dmean & 30.0 & 30.2 & 30.7 & 30.0 \\
\hline & D98\% & 22.9 & 23.1 & 23.0 & 22.5 \\
\hline & $\mathrm{D} 2 \%$ & 41.3 & 41.0 & 41.6 & 41.2 \\
\hline \multirow{4}{*}{$\begin{array}{l}\text { Urinary } \\
\text { bladder }\end{array}$} & Dmean & 29.9 & 30.1 & 30.2 & 30.1 \\
\hline & $\mathrm{D} 2 \%$ & 11.5 & 11.5 & 11.9 & 11.6 \\
\hline & D50\% & 31.2 & 31.4 & 31.5 & 31.4 \\
\hline & D98\% & 50.3 & 50.2 & 50.4 & 50.4 \\
\hline \multirow[t]{3}{*}{ Genitalia } & Dmean & 20.5 & 21.0 & 22.0 & 22.6 \\
\hline & D98\% & 5.5 & 5.9 & 6.4 & 6.5 \\
\hline & D2\% & 43.8 & 45.0 & 44.8 & 44.7 \\
\hline \multirow{4}{*}{$\begin{array}{l}\text { Testis } \\
(n=4)\end{array}$} & Dmean & 6.4 & 7.1 & 8.0 & 10.2 \\
\hline & D98\% & 2.1 & 2.4 & 2.6 & 3.0 \\
\hline & D50\% & 5.3 & 5.5 & 6.4 & 7.9 \\
\hline & $\mathrm{D} 2 \%$ & 16.8 & 20.5 & 22.1 & 25.1 \\
\hline \multirow{4}{*}{$\begin{array}{l}\text { Vulva } \\
(n=8)\end{array}$} & Dmean & 16.2 & 16.5 & 17.1 & 18.2 \\
\hline & D98\% & 5.3 & 6.3 & 6.8 & 6.6 \\
\hline & D50\% & 13.6 & 13.6 & 14.4 & 16.6 \\
\hline & $\mathrm{D} 2 \%$ & 35.1 & 36.2 & 35.6 & 35.8 \\
\hline \multirow{4}{*}{$\begin{array}{l}\text { Small } \\
\text { bowel loops }\end{array}$} & $20 \mathrm{cc}$ & 48.8 & 48.7 & 48.8 & 48.9 \\
\hline & $65 \mathrm{cc}$ & 45.0 & 44.9 & 45.0 & 44.9 \\
\hline & $150 \mathrm{cc}$ & 38.8 & 38.7 & 38.5 & 38.4 \\
\hline & $200 \mathrm{cc}$ & 35.6 & 35.5 & 35.4 & 35.2 \\
\hline
\end{tabular}

Bold values statistically significant difference to RTOG

The dose coverage of all PTVs was accurately performed, which resulted in a mean V95\% of $100 \%$ and a mean median dose of $50.0 \mathrm{~Gy}$ for all PTV ${ }^{\text {sum }}$. The mean maximal dose (D2\%) came to 52.4Gy (104\%) and the mean minimal dose (D98\%) was between 36.2 and $39.8 \mathrm{~Gy}$ for all PTV sum. The mean V95\% of the PTV ing was at least 98\% after the PTVs had been defined in accordance with the instructions of the four different guidelines.

\section{Dose distribution to organs at risk}

We evaluated various relevant relative and absolute dose parameters of the rectum, sigmoid colon, small bowel loops, femoral heads, urinary bladder, genitalia, and skin. The results are summarized in Table 2 and 3.

There was no significant difference in dose distribution in the cranially located OARs. The rectum was almost completely included in the different PTVs in all patients (D98\%
Table 3 Relative dose parameters of organs at risk for different cranial PTVs

\begin{tabular}{|c|c|c|c|c|c|}
\hline Structure & Parameter & RTOG & AGITG & $\mathrm{BNG}$ & TUM \\
\hline- & - & \multicolumn{4}{|c|}{ Volume (\%) } \\
\hline \multirow[t]{2}{*}{ Rectum } & V45 Gy & 100 & 100 & 100 & 100 \\
\hline & V50Gy & 66 & 65 & 63 & 65 \\
\hline \multirow{4}{*}{$\begin{array}{l}\text { Sigmoid } \\
\text { Colon }\end{array}$} & V20 Gy & 98 & 98 & 98 & 98 \\
\hline & V30 Gy & 91 & 92 & 91 & 91 \\
\hline & V40Gy & 85 & 85 & 84 & 85 \\
\hline & V50Gy & 8 & 7 & 8 & 7 \\
\hline \multirow{5}{*}{$\begin{array}{l}\text { Urinary } \\
\text { bladder }\end{array}$} & V10Gy & 89 & 89 & 90 & 87 \\
\hline & V20 Gy & 65 & 68 & 67 & 66 \\
\hline & V30Gy & 43 & 43 & 44 & 44 \\
\hline & V40Gy & 32 & 32 & 32 & 32 \\
\hline & V50 Gy & 7 & 7 & 8 & 8 \\
\hline \multirow{3}{*}{$\begin{array}{l}\text { Femoral } \\
\text { head }\end{array}$} & V20 Gy & 100 & 100 & 100 & 100 \\
\hline & V30Gy & 44 & 46 & 50 & 45 \\
\hline & V40 Gy & 5 & 4 & 6 & 5 \\
\hline \multirow[t]{5}{*}{ Genitalia } & V10Gy & 78 & $81^{\mathrm{a}}$ & 84 & 83 \\
\hline & V20 Gy & 43 & 44 & 48 & 50 \\
\hline & V30Gy & 19 & 19 & 22 & 27 \\
\hline & V40Gy & 12 & 12 & 12 & 15 \\
\hline & V50Gy & 2 & 2 & 3 & 2 \\
\hline Testis & V3 & 17 & 20 & 23 & 24 \\
\hline Vulva & V30 & 12 & 12 & 12 & 17 \\
\hline- & - & \multicolumn{4}{|c|}{ Volume (cc) } \\
\hline \multirow{5}{*}{$\begin{array}{l}\text { Small bowel } \\
\text { loops }\end{array}$} & V10Gy & 527 & 528 & 527 & 526 \\
\hline & V20 Gy & 438 & 435 & 436 & 437 \\
\hline & V30Gy & 302 & 297 & 300 & 296 \\
\hline & V40Gy & 193 & 192 & 194 & 198 \\
\hline & V50 Gy & 32 & 32 & 33 & 32 \\
\hline \multirow[t]{5}{*}{ Skin } & V10Gy & 358 & 388 & 396 & 398 \\
\hline & V20 Gy & 80 & 96 & 108 & 107 \\
\hline & V30 Gy & 16 & 22 & 29 & 28 \\
\hline & V35 Gy & 7 & 9 & 11 & 11 \\
\hline & V50 Gy & 1 & 1 & 1 & 1 \\
\hline
\end{tabular}

Bold values statistically significant difference to RTOG

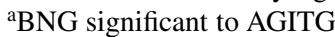

$>48.8$ Gy). Since the cranial margins of the individual PTVs were identical, there were no significant differences between the dose parameters of the small bowel loops. The mean dose to $65 \mathrm{cc}$ and $200 \mathrm{cc}$ was about 45 and $35 \mathrm{~Gy}$, respectively, for all groups. The relative and absolute doses to the femoral heads and the urinary bladder did not show any significant differences between the four target volumes, either. The Dmean was about 30Gy for both structures. The mean V40Gy of the urinary bladder did not reach more than $40 \%$ and the mean V30 Gy of the femoral heads was $50 \%$ or less.

The dose parameters to the genitalia and the skin, unlike those to the pelvic and abdominal risk structures, showed significant differences. The mean Dmean to the genitalia of 

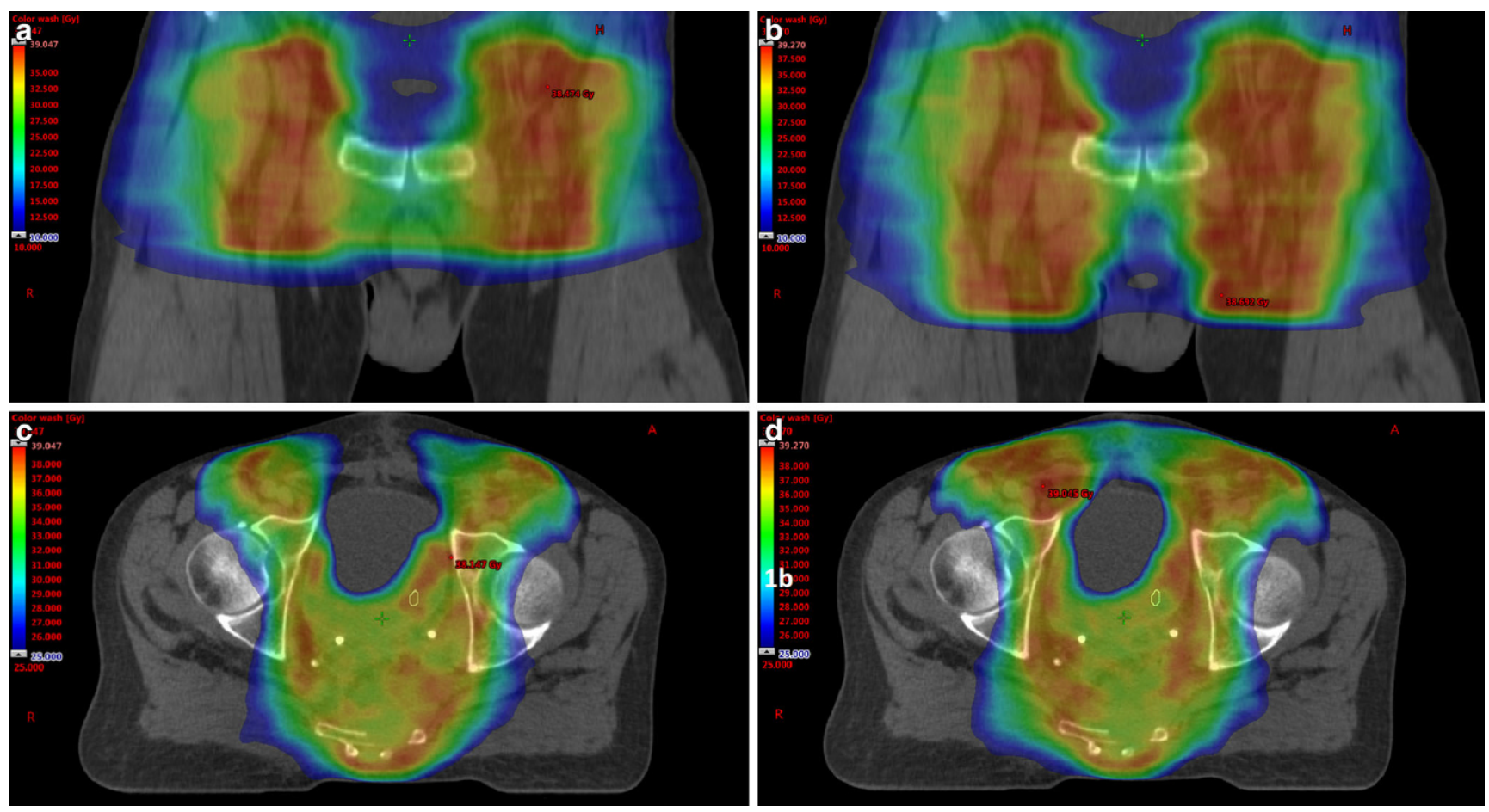

Fig. 2 Differences in inguinal dose distribution using the clinical target volume (CTV) definition of the Radiation Therapy Oncology Group (RTOG; a and c) and the British National Guidance (BNG; b and d). Axial color wash: 25 Gy (dark blue)-39 Gy (dark red). Transversal color wash: $10 \mathrm{~Gy}$ (dark blue) $-39 \mathrm{~Gy}$ (dark red). CTV of BNG expands more caudally and medially and leads to a significantly greater dose to the skin and the genitalia

both sexes was about $20 \mathrm{~Gy}$ in all plans. However, there was a significant difference between BNG (22Gy) and RTOG $(20.5 \mathrm{~Gy} ; p=0.016)$. The $\mathrm{D} 98 \%$ of the BNG $(6.4 \mathrm{~Gy})$ and the LI (6.5 Gy) was significantly higher than the D98\% of the RTOG (5.3 Gy; $p=0.001$ and $p=0.016$, respectively). Despite minor absolute differences, the V10 Gy of the BNG (84\%) was significantly higher than those of the RTOG (78\%, $p=0.016)$ and the AGITG $(81 \%, p=0.043)$. The same applies to the V20Gy. While it was $48 \%$ with the $\mathrm{BNG}$, it was $43 \%$ with the RTOG $(p=0.016)$. Concerning the vulva (eight patients), the dose parameters did not differ greatly.

The skin turned out to be the organ showing the greatest differences between the dose parameters of the four target volumes. All in all, the results in the BNG and LI groups were the highest and comparable to each other, while the RTOG results were the lowest. The V10-V20 Gy values were significantly lower in the RTOG $(358 \mathrm{cc}$ and $80 \mathrm{cc}$ ) compared to the three other guidelines $(388-398 \mathrm{cc}$ and 96-107 cc). So were V30 Gy and V35 Gy compared to the BNG and the LI $(p<0.004)$. Low doses fluctuated less than higher doses. In the BNG group, for example, the V10 Gy was only about $10 \%$ higher $(398 \mathrm{cc}$ ) than the V10 Gy in the RTOG $(358 \mathrm{cc})$, whereas the clinically more relevant V30 Gy was almost twice as high in the BNG group as in the RTOG ( $29 \mathrm{cc}$ vs. $16 \mathrm{cc}, p=0.000$ ).

\section{Discussion}

We retrospectively evaluated the dose to OAR in twelve patients by using three established international contouring guidelines and one guidance created by the LI for the definition of the elective target volume for IMRT of primary anal cancer. According to the guidelines of the National Comprehensive Cancer Network (NCCN, 2018), IMRT is preferred over $3 \mathrm{D}$ conformal RT. The anus and the perineum as well as the pelvic and inguinal LNs should be included in the target volume [19]. Although current contouring atlases refer to IMRT, the common constraints are often related to 3D conformal irradiation [20].

Pelvic region: The recommendations of the various guidelines concerning the radial margins of the CTV for the pelvis differ only marginally (Table 1). Especially the cranial margins are identical, since all internal and external iliac nodes up to the bifurcation of the common iliac vessels should be included in the CTV. In our study, the dose parameters were slightly higher than the constraints of $30 \mathrm{~Gy}$ $(200 \mathrm{cc})$ and $35 \mathrm{~Gy}(150 \mathrm{cc})$, respectively, recommended by RTOG 0529 [12]. One explanation may be the fact that, depending on tumor stage, the dose prescription of elective LNs was $42 \mathrm{~Gy}$ or $45 \mathrm{~Gy}$ in RTOG 0529 . In contrast to this, we prescribed $50.4 \mathrm{~Gy}$. Furthermore, the V30 Gy and 

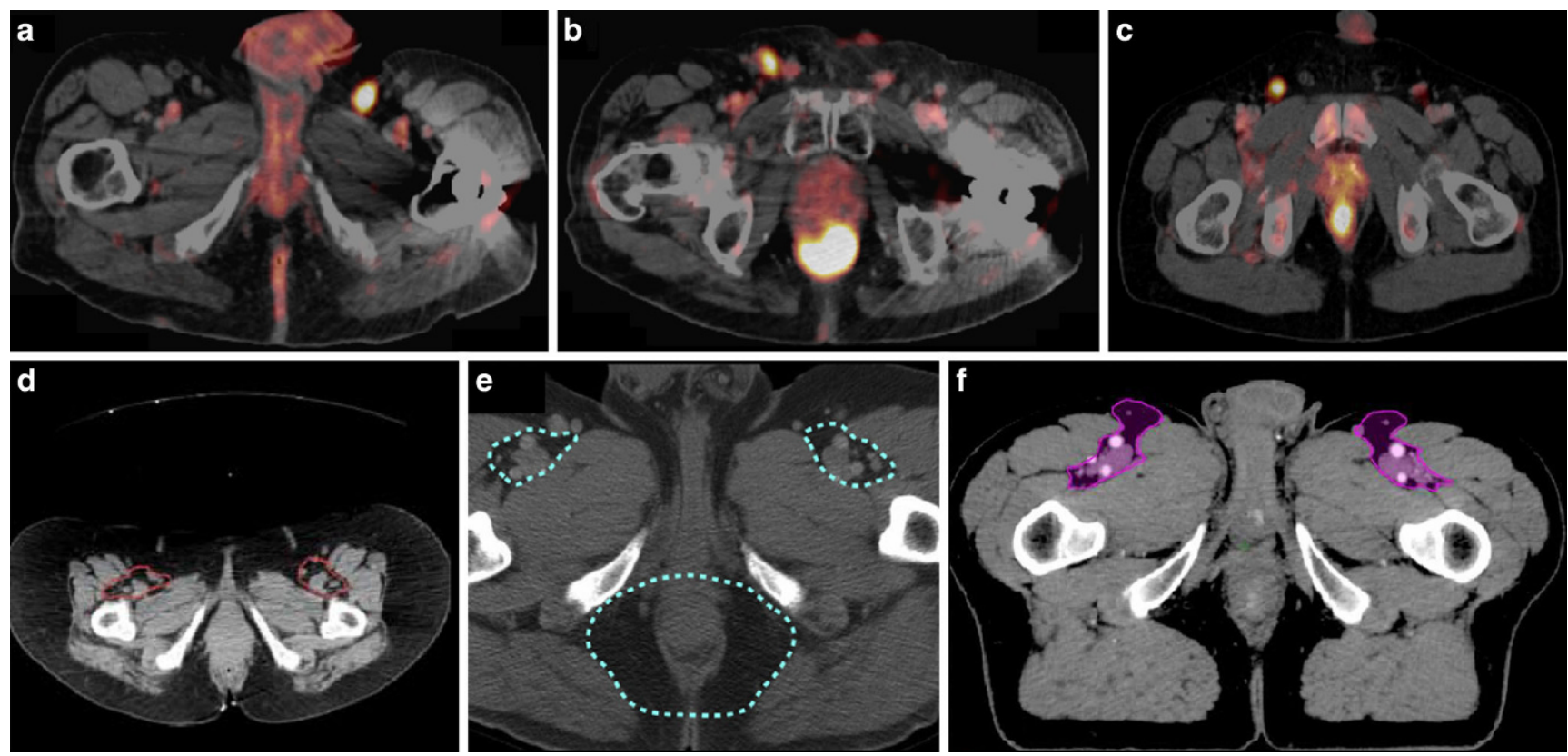

Fig. 3 PET-positive superomedial superficial inguinal lymph nodes (LNs) (a-c) in patients with primary diagnosis of anal cancer. The LNs were possibly not properly covered by the elective clinical target volume (CTV) recommendations of the Radiation Therapy Oncology Group (RTOG, red outline; d) and the Australasian Gastrointestinal Trials Group (AGITG, turquoise outline; e), but completely included in the CTV of the British National Guidance (BNG, purple outline; $\mathbf{f})$

V40Gy have been identified as significant dose parameters regarding acute gastrointestinal toxicity using IMRT in anal cancer patients. DeFoe et al. suggest a V30 Gy $\leq 310 \mathrm{cc}$ and $\mathrm{V} 40 \mathrm{~Gy} \leq 70 \mathrm{cc}$ to avoid $\geq$ grade 3 toxicity (CTCAE), while Devisetty et al. observed a correlation between V30 Gy $>450 \mathrm{cc}$ with $2 \mathrm{~B}$ and higher (RTOG) gastrointestinal toxicity $[21,22]$. All four groups came up with the V30 Gy $\leq 310 \mathrm{cc}$ (about $300 \mathrm{cc}$ ) while the V40 Gy was about $200 \mathrm{cc}$. A further argument for the rather high dose prescription for the pelvic lymph drainage is in our opinion the fact that in four patients, the PTV was slightly above the bifurcation of the iliac artery due to extensive locoregional LN involvement. In addition, due to anatomical conditions, the urinary bladder is not greatly influenced by the different PTVing.

Inguinal region: The total dose of the elective inguinal target volume used in large prospective trials ranges from 30.6 Gy (ACT II) to 45 Gy (RTOG 98-11), which means an enormous divergence $[1,2]$. As there is still uncertainty about the optimal elective dose to the inguinal region, we opted for a compromise and chose a total prescription dose of $36 \mathrm{~Gy}$. While the target volumes and the dose to OARs hardly differed in the pelvis, there were large differences in the inguinal region between the guidelines. The BNG and LI groups recommend inclusion of the superomedial LNs (spermatic cord in men). This means that the CTV below the groin extends much further medially than the CTV suggested by the RTOG and the AGITG. The BNG group suggest that the CTV should reach up to $5 \mathrm{~mm}$ to the skin. The most obvious differences between the recommendations of the individual groups can be found with regard to the caudal margin of the elective CTV (Table 1; Fig. 1). Here, the height of bony structures (ischial tuberosities/ AGITG, trochanter/BNG) as well as soft tissue structures ( $2 \mathrm{~cm}$ caudal to the saphenous femoral junction/RTOG; height of anal verge/LI) is recommended. In a previous study, we were able to show that the anatomical relationships between these soft tissue structures and bony structures differ significantly between patients [10]. Therefore, evidence-based recommendations for target volume definition of the inguinal region in anal cancer are needed.

The fundamentally dreaded side effects of radiotherapy to the groin are lymphatic edema caused by inguinal fibrosis. The pronounced medial and caudal extensions of the target volume suggested by the BNG and LI groups lead in part to significantly higher dose rates to the genitals (Fig. 2; Tables 2, 3). Regarding RTOG 0630 (sarcoma), the median dose to the testis should not extend $3 \mathrm{~Gy}$ [23]. In each group, the median dose to the testis was higher than $5 \mathrm{~Gy}$. Even if the absolute dose to the testicles is relatively low, we recommend considering special protection of the genitals. The D50\% of the vulva was below $17 \mathrm{~Gy}$ in each group (RTOG 0529 constraints: 30 Gy). The risk of developing genital lymphedema is very low if a relatively low dose of $36 \mathrm{~Gy}$ is prescribed. The University of Florida presented long-term toxicity in 164 patients after elective radiation ( $>70 \%$ of the patients with $\geq 45 \mathrm{~Gy}$ ) of the groin in pelvic 
cancers. Only three of them developed mild genital edema [24].

The greatest relative and absolute differences concerning the dose parameters between the different CTVs related to the skin. We authenticated a correlation between the skin dose and the inguinal PTV volumes. The caudal margin of the CTV is especially responsible for an increased volume. This is due to the fact that the inferior aspect of the minor tuberculum (BNG) and the level of the anal verge (LI) are usually situated lower than the ischial tuberosities (AGITG) or $2 \mathrm{~cm}$ below the femoral saphenous junction (RTOG; Fig. 1). The inguinal target volume was almost twice as high in the BNG and LI groups compared to RTOG (V30 Gy and V35 Gy, respectively). This aspect, however, seems to be of minor clinical relevance since the absolute dose radiation to the groin $(36 \mathrm{~Gy})$ is relatively low. Lee et al. identified 13 of 164 patients (8\%) with inguinal fibrosis after elective radiation ( $>70 \%$ of the patients with $\geq 45 \mathrm{~Gy}$ ) of the groin. None of these cases was severe or correlated with a decrease in quality of life [24].

To make clear recommendations for contouring of the inguinal region, results of studies dealing with the site of locoregional failure after IMRT of AC patients should be taken into consideration. Tomasoa et al. presented patterns of recurrence in 106 patients treated with simultaneously integrated boost (SIB) IMRT. After a median follow-up of 15 months, about $20 \%$ of the patients had locoregional relapse. Only two LN recurrences occurred at a pelvic site, while at least four patients had inguinal recurrences $(4 \%$, $6 \mathrm{LN}$ ) [25]. Furthermore, potential inguinal misses such the ones on superficial superomedial LNs could be identified in a PET imaging-based pattern of failure analysis in the context of established contouring guidelines ([26]; Fig. 3). Finally, the risk of relevant side effects due to slightly larger inguinal target volumes (BNG, LI) seems to be low, since both the absolute size differences and the prescribed dose are manageable, while inguinal recurrence is still relevant.

Limitations: All in all, we evaluated a small number of patients. In daily practice, physicians perform a risk-adapted contouring of individual cases with individual anatomy, which will certainly differ from the different guidelines. Moreover, it is difficult to standardize terms like "the inguinal region should be contoured as a compartment with any identified nodes." Therefore, the CTVs we created can only be seen as an approximation of an elective "standard" CTV of the respective guidelines. The data, however, provide valuable information on the possibilities of contouring in anal cancer.

\section{Conclusion}

The four contouring guidelines differ significantly concerning the inguinal region. In order to avoid inguinal recurrence and to protect relevant OARs, further investigations are needed to generate uniform standards for the definition of the elective clinical target volume in the inguinal region.

Funding This research did not receive any funds from funding agencies in public, commercial, or not-for-profit sectors.

Authors' contribution SC treated the patients and provided the data and study infrastructure. HD developed the study design, collected and interpreted data, performed statistical analysis, and drafted the manuscript. MO calculated the treatment plans. HD, MO, and SC made substantial contributions to conception and design of the study, interpreted data, and revised the manuscript. $\mathrm{SM}, \mathrm{KB}, \mathrm{CD}$, and $\mathrm{SC}$ contributed significantly to the discussion and interpretation of the results. All coauthors read and revised the manuscript. The final version of the manuscript was approved by all coauthors.

Data availability The present data are summarized in this paper ("Methods"). The complete dataset can be obtained from the authors by interested readers upon formal request.

Funding Open Access funding provided by Projekt DEAL.

\section{Compliance with ethical guidelines}

Conflict of interest H. Dapper, M. Oechsner, S. Münch, C. Diehl, J.C. Peeken, K. Borm, and S.E. Combs declare that they have no competing interests.

Ethical standards The study was performed in accordance with the ethics standards at the Technical University of Munich (ethical vote: 385/18 s). Name of committee: Ethikkommission der Technischen Universität München.

Open Access This article is licensed under a Creative Commons Attribution 4.0 International License, which permits use, sharing, adaptation, distribution and reproduction in any medium or format, as long as you give appropriate credit to the original author(s) and the source, provide a link to the Creative Commons licence, and indicate if changes were made. The images or other third party material in this article are included in the article's Creative Commons licence, unless indicated otherwise in a credit line to the material. If material is not included in the article's Creative Commons licence and your intended use is not permitted by statutory regulation or exceeds the permitted use, you will need to obtain permission directly from the copyright holder. To view a copy of this licence, visit http://creativecommons.org/licenses/by/4. $0 \%$

\section{References}

1. Ajani JA, Winter KA, Gunderson LL et al (2008) Fluorouracil, mitomycin, and radiotherapy vs fluorouracil, cisplatin, and radiotherapy for carcinoma of the anal canal: a randomized controlled trial. JAMA 299(16):1914-1921. https://doi.org/10.1001/jama.299. 16.1914

2. James RD, Glynne-Jones R, Meadows HM et al (2013) Mitomycin or cisplatin chemoradiation with or without maintenance chemotherapy for treatment of squamous-cell carcinoma of the 
anus (ACT II): a randomised, phase 3, open-label, 2 × 2 factorial trial. Lancet Oncol 14(6):516-524. https://doi.org/10.1016/S14702045(13)70086-X

3. Cardenas ML, Spencer CR, Markovina S et al (2017) Quantitative FDG-PET/CT predicts local recurrence and survival for squamous cell carcinoma of the anus. Adv Radiat Oncol 2(3):281-287. https:// doi.org/10.1016/j.adro.2017.04.007

4. Muirhead R, Adams RA, Gilbert DC, Harrison M, Glynne-Jones R, Sebag-Montefiore D, Hawkins MA (2016) National guidance for IMRT in anal national guidance for IMRT in anal cancer. http://analimrtguidance.co.uk/national-anal-imrt-guidance-v3.pdf. Accessed 8 Aug 2018

5. Myerson RJ, Garofalo MC, El Naqa I et al (2009) Elective clinical target volumes for conformal therapy in anorectal cancer: a radiation therapy oncology group consensus panel contouring atlas. Int J Radiat Oncol Biol Phys 74(3):824-830. https://doi.org/10.1016/j. ijrobp.2008.08.070

6. Ng M, Leong T, Chander S et al (2012) Australasian Gastrointestinal Trials Group (AGITG) contouring atlas and planning guidelines for intensity-modulated radiotherapy in anal cancer. Int $\mathrm{J}$ Radiat Oncol Biol Phys 83(5):1455-1462. https://doi.org/10.1016/j.ijrobp. 2011.12.058

7. Bilimoria KY, Bentrem DJ, Rock CE et al (2009) Outcomes and prognostic factors for squamous-cell carcinoma of the anal canal: analysis of patients from the National Cancer Data Base. Dis Colon Rectum 52(4):624-631. https://doi.org/10.1007/DCR. 0b013e31819eb7

8. Deans GT, McAleer JJ, Spence RA (1994) Malignant anal tumours. Br J Surg 81(4):500-508

9. Gerard JP, Chapet O, Samiei F et al (2001) Management of inguinal lymph node metastases in patients with carcinoma of the anal canal: experience in a series of 270 patients treated in Lyon and review of the literature. Cancer 92(1):77-84

10. Dapper H, Schiller K, Münch S et al (2019) Have we achieved adequate recommendations for target volume definitions in anal cancer? A PET imaging based patterns of failure analysis in the context of established contouring guidelines. BMC Cancer 19(1):742. https://doi.org/10.1186/s12885-019-5970-0

11. Mitchell MP, Abboud M, Eng C et al (2014) Intensity-modulated radiation therapy with concurrent chemotherapy for anal cancer: outcomes and toxicity. Am J Clin Oncol 37(5):461-466. https://doi. org/10.1097/COC.0b013e31827e52a3

12. Kachnic LA, Winter K, Myerson RJ et al (2013) RTOG 0529: a phase 2 evaluation of dose-painted intensity modulated radiation therapy in combination with 5-fluorouracil and mitomycin- $\mathrm{C}$ for the reduction of acute morbidity in carcinoma of the anal canal. Int J Radiat Oncol Biol Phys 86(1):27-33. https://doi.org/10.1016/j. ijrobp.2012.09.023

13. Mirabeau-Beale K, Hong TS, Niemierko A et al (2015) Clinical and treatment factors associated with vaginal stenosis after definitive chemoradiation for anal canal cancer. Pract Radiat Oncol 5(3):e113-e118. https://doi.org/10.1016/j.prro.2014.09.003

14. Call JA, Prendergast BM, Jensen LG et al (2016) Intensity-modulated radiation therapy for anal cancer: results from a multi-institutional retrospective cohort study. Am J Clin Oncol 39(1):8-12. https://doi.org/10.1097/COC.0000000000000009
15. Knowles G, Haigh R, McLean C et al (2015) Late effects and quality of life after chemo-radiation for the treatment of anal cancer. Eur J Oncol Nurs 19(5):479-485. https://doi.org/10.1016/j.ejon.2015. 02.007

16. Gay HA, Barthold HJ, O’Meara E et al (2012) Pelvic normal tissue contouring guidelines for radiation therapy: a Radiation Therapy Oncology Group consensus panel atlas. Int J Radiat Oncol Biol Phys 83(3):e353-e362. https://doi.org/10.1016/j.ijrobp.2012.01. 023

17. Brooks C, Hansen VN, Riddell A et al (2015) Proposed genitalia contouring guidelines in anal cancer intensity-modulated radiotherapy. Br J Radiol 88(1051):20150032. https://doi.org/10.1259/bjr. 20150032

18. International Commission on Radiation Units and Measurements (2010) Prescribing, recording, and reporting photon-beam intensity-modulated radiation therapy (IMRT). Journal of the ICRU, vol 10. Oxford University Press, Oxford

19. Benson AB, Venook AP, Al-Hawary MM et al (2018) Anal carcinoma, version 2.2018, NCCN clinical practice guidelines in oncology. J Natl Compr Canc Netw 16(7):852-871. https://doi.org/10. 6004/jncen.2018.0060

20. Marks LB, Yorke ED, Jackson A et al (2010) Use of normal tissue complication probability models in the clinic. Int $\mathrm{J}$ Radiat Oncol Biol Phys 76(3 Suppl):S10-S19. https://doi.org/10.1016/j.ijrobp. 2009.07.1754

21. DeFoe SG, Kabolizadeh P, Heron DE et al (2013) Dosimetric parameters predictive of acute gastrointestinal toxicity in patients with anal carcinoma treated with concurrent chemotherapy and intensity-modulated radiation therapy. Oncology 85(1):1-7. https://doi. org/10.1159/000348387

22. Devisetty K, Mell LK, Salama JK et al (2009) A multi-institutional acute gastrointestinal toxicity analysis of anal cancer patients treated with concurrent intensity-modulated radiation therapy (IMRT) and chemotherapy. Radiother Oncol 93(2):298-301. https://doi.org/10.1016/j.radonc.2009.07.006

23. Wang D, Zhang Q, Eisenberg BL et al (2015) Significant reduction of late toxicities in patients with extremity sarcoma treated with image-guided radiation therapy to a reduced target volume: results of radiation therapy oncology group RTOG-0630 trial. J Clin Oncol 33(20):2231-2238. https://doi.org/10.1200/JCO.2014.58.5828

24. Lee WR, McCollough WM, Mendenhall WM et al (1993) Elective inguinal lymph node irradiation for pelvic carcinomas. The University of Florida experience. Cancer 72(6):2058-2065

25. Tomasoa NB, Meulendijks D, Nijkamp J et al (2016) Clinical outcome in patients treated with simultaneous integrated boost-intensity modulated radiation therapy (SIB-IMRT) with and without concurrent chemotherapy for squamous cell carcinoma of the anal canal. Acta Oncol 55(6):760-766. https://doi.org/10. 3109/0284186X.2015.1124141

26. Dapper H, Habl G, Hirche C et al (2018) Dosimetric quantification of the incidental irradiation of the "true" (deep) ano-inguinal lymphatic drainage of anal cancer patients not described in conventional contouring guidelines. Acta Oncol. https://doi.org/10.1080/ 0284186X.2017.1415459 